\title{
Is Hypothetical Bias a Universal Phenomenon? A Multinational Investigation
}

\author{
Mariah D. Ehmke, Jayson L. Lusk, and John A. List
}

\begin{abstract}
A concern with the contingent valuation method (CVM) is the finding that hypothetical and real statements of value often differ. We test whether hypothetical bias, broadly defined, is independent of location by comparing real and hypothetical votes on a dichotomous choice referendum in China, France, Indiana, Kansas, and Niger. We find significant differences in hypothetical bias across locations and reject the hypothesis that hypothetical bias is independent of location. As opposed to the typical finding reported in the literature, subjects in Niger significantly understated their willingness-topay in the hypothetical referendum. (JEL Q51)
\end{abstract}

The contingent valuation method (CVM) is a popular tool to value changes in environmental amenities and is increasingly being used to value new technologies and private good attributes. ${ }^{1}$ The CVM, and other similar survey-based methods such as conjoint analysis, are often the only feasible modeling alternatives if the analyst is interested in obtaining the total value (i.e., both the use and non-use value) of a good or service. Recently, there has been a lively debate about whether and to what extent hypothetical bias permeates benefit estimation in contingent markets and whether the phenomenon complicates obtaining reliable measures of value (see, e.g., List et al. 2004). Simply defined, hypothetical bias is the difference between hypothetical and actual statements of value. A host of possible causes for the bias have been proposed, including strategic survey response (e.g., Carson, Groves, and Machina 2007), un-

\footnotetext{
1 "Contingent valuation" refers to a set of surveybased approaches for eliciting Hicksian compensating or equivalent surplus values for a hypothetical change in a good or program.
}

Land Economics • August 2008 • 84 (3): 489-500 ISSN 0023-7639; E-ISSN 1543-8325

(C) 2008 by the Board of Regents of the University of Wisconsin System certainty about one's value for the good (e.g., Champ and Bishop 2001; Johannesson et al. 1999), commitment costs or option values (e.g., Norwood, Lusk, and Boyer 2008), and social desirability bias (List et al. 2004; Lusk and Norwood 2008); however, there seems to be little consensus on the key mechanisms driving a wedge between real and hypothetical statements of value. While the finding of such bias is widespread (e.g., see List and Gallet 2001), there is a notable commonality amongst such studies-most, if not all, have been conducted in the United States or in western Europe. Whether hypothetical bias is identical across culturally distinct consumer groups remains an open empirical question. Indeed, we know of no such evidence in the literature.

While hypothetical bias may appear to be an innocuous issue, it has implications for international benefit-transfer and consumer valuation. Contingent valuation is commonly used to carry out benefit-cost analysis, a technique increasingly used around the globe to improve the quality of government decisionmaking. Indeed, in the United States, every "economically significant" rule-

The authors are, respectively, assistant professor, Department of Agricultural and Applied Edonomics, University of Wyoming, professor and Willard Sparks Endowed Chair, Department of Agricultural Economics, Oklahoma State University, and professor, Department of Economics, University of Chicago. The authors wish to thank the following individuals for helpful comments on previous versions of the paper and/or providing assistance in conducting the experiments: an anonymous referee, Glenn Harrison, Myrdene Anderson, Tomas Nilsson, Cole Ehmke, Tony Torres, Glynn Tonsor, Sean Fox, Virginia Moxley, Carmel White, Min Wang, Jia Lv, Zuhui Huang, Tahirou Abdoulaye, Germain Ibro, Abdoulaye Mohammed, Moustpha Moussa, Bokar Moussa, Stephané Robin, and Bernard Ruffieux. This work is made possible through funding from the United States Department of Agriculture, Purdue Research Foundation, Kappa Kappa Gamma, and the American Association of University Women. 
making must undergo a formal benefit-cost analysis by the federal agency proposing the new rule. ${ }^{2}$ Such requirements, which are also becoming more common at lower levels of government, place great financial strains on a system already short of the necessary resources to govern effectively. In response, policymakers have relied on existing benefit estimates rather than producing an entirely new set of empirical estimates. This approach by now has become universal, and the practice of benefit transfer is second nature to many policymakers. ${ }^{3}$

If the benefit transfer method is to be applied across nations, an important first consideration is whether the degree of hypothetical bias is location specific. Likewise, as globalization relaxes the spatial boundaries of markets, there is an increasing need to understand consumer valuation of international policies and goods. ${ }^{4}$ This is especially true regarding benefit transfer for environmental goods where some consumer differences (e.g., real income) are more easily accounted for than others, like culture (Ready and Navrud 2006). Previous studies of international benefit transfer have not investigated the role hypothetical bias plays in proficient benefit transfer, especially

\footnotetext{
${ }^{2}$ An economically significant rule is one which is expected to exceed $\$ 100$ million in either annual benefits or costs. About 50-100 proposed rules are considered economically significant every year in the United States.

3 "Benefit transfer" is similar in spirit to policymakers measuring rents associated with changes in price levels. The interested reader should see the studies presented at a recent EPA conference on the benefit-transfer technique: https://www2.ergweb.com/projects/conferences/ncee/agenda. htm.

${ }^{4}$ One example of this type of policy is the Kyoto Protocol, which calls upon nations to reduce their greenhouse gas emissions. Because most of the benefits accruing from this policy are non-market benefits, CVM represents one of the easiest ways to estimate values that can be weighted against costs. It is difficult, however, to know whether benefit measures from the CVM can be directly aggregated across cultures so that the merits of international policies can be judged. Another realm for which this issue is becoming increasingly important concerns food marketing and policy - it is invaluable to understand whether CVM valuations can be interpreted in a uniform manner across all cultures and groups. This determination will provide the basis of achieving efficient policy with regard to global environmental regulations, food safety standards, and technology standardization.
}

across culturally divergent groups; rather, they focus on other economic and demographic factors such as income, age, price sensitivity, environmental risk, and household size (e.g., Bateman et al. 2005; Brouwer and Bateman 2005; Ready et al. 2004).

Culture itself may be broadly defined as the socially learned patterns of thinking, feeling, and acting. The influence of culture on the individual begins in childhood and continues throughout life (Hofstede 1991). Given the pervasiveness with which culture, often subconsciously, influences beliefs and perhaps even shapes preferences, it is quite possible that culture may influence hypothetical bias. For example, it is known that individuals' tolerance for risk is culturally influenced as are a number of other factors including the extent to which people are more or less individualistic (Douglas 1985; Hoftstede 1991). Several of these cultural factors may relate to hypothetical bias. For example, if the bias results from agent's uncertainty about the value for a good, as argued by Champ and Bishop (2001), then culture, because it affects preference for risk, might relate to the bias. Further, previous research suggests that strategic thinking and behavior are influenced by culture (Roth et al. 1991; Henrich et al. 2001); thus, to the extent that hypothetical bias is caused by strategic survey responses, as argued by Carson, Groves, and Machina (2007), the bias is also caused by culture. ${ }^{5}$

In the spirit of Roth et al. (1991), whose seminal experiment studied the effect of culture on bargaining outcomes, the primary purpose of this work is to measure hypothetical bias in several distinct cultural groups to determine whether valuations can be transferred from one country to another and whether valuations can be aggregated across countries. In particular, we compare

\footnotetext{
${ }^{5}$ Methods exist to account for cultural factors (e.g., see Hofstede's Value Survey Model in the Appendix or see http://www.geert-hofstede.com/ for measures of cultural dimensions for a variety of countries) which may influence hypothetical bias. If cultural factors influence hypothetical bias, such tools may be useful in developing calibration techniques to enhance the effectiveness of the benefit-transfer technique in the international arena.
} 
hypothetical and real votes in a collective choice mechanism that provides each individual with bottled water if funded. Individuals in Hangzhou, China; Niamey, Niger; Grenoble, France; Manhattan, Kansas; and West Lafayette, Indiana, participated in separate, but identical, experiments. Our results provide initial evidence that current benefit-transfer techniques might be considerably biased. For example, we find that hypothetical bias differs markedly across space: whereas we find considerable evidence of hypothetical bias in the U.S. samples, we find much less evidence of such bias in Niger, France, and China. Due to the manner in which our treatments were executed, heterogeneities in hypothetical bias are not due to differences in the experimental environment. Our preferred interpretation is that cultural differences contribute to this behavioral disparity, as measured cultural characteristics can partly explain differences in hypothetical bias observed across space.

\section{METHODOLOGY AND DATA COLLECTION}

Experimental data gathered from student subjects in Hangzhou, China; Niamey, Niger; Grenoble, France; Manhattan, Kansas; and West Lafayette, Indiana are used to investigate whether CVM responses vary spatially across hypothetical and real scenarios. These locations were selected based on their cultural distinctness from one another and because of the environmental and international policy importance of the respective nations. For example, the French culture is expected to be more feminine (less masculine) than the American culture (Hofstede 1991). ${ }^{6}$ Similarly, the French and Americans are both from more individualistic societies than the Chinese and Nigerien groups. At the same time, each location is of international policy import. The United States and France are both key leaders and

\footnotetext{
${ }^{6}$ Hofstede describes culture's feminine dimension as the cultural tendency toward which gender roles are overlapping and tenderness, caring, and supportive behavior is encouraged (Hofstede 1991).
}

decisionmakers on the international scene. Niger is important as a net recipient of international aid and policy support. China is included as it is an increasingly important player in the international environmental and economic policy arenas.

Our experimental methodology combines the careful use of cross-cultural experimentation (Roth et al. (1991)) with the collective choice mechanism of List (2004). Because the degree of hypothetical bias has been found to depend critically on the nature of the good, as an initial exploration into this issue it is important to consider a good which is universally consumed and does not induce social pressures. We chose bottled mineral water as the good to be valued because it is available and consumed in each country and valuations for water are overly susceptible to seasonal differences (as would be the case if we were valuing outdoor recreational activities, for example). In every country but Niger, the water was domestically produced and bottled in the respective country (the water in Niger was from Burkina Faso).

Data were collected in the spring of 2004 at universities in each city. In each location, university students were randomly recruited to take part in an economics experiment where they could be expected to earn a reasonable sum of money. Upon arrival at an experimental session, individuals signed a consent form and proceeded to participate in a series of different experiments. The expected earnings from all of the experiments and survey completion were about \$US 25. The total experiment sessions (including all experiments, survey, and payments) ran an average of one hour in length. At the conclusion of the experiment, subjects completed the Values Survey Module (VSM) based on Hofstede's $(1980,1991)$ which is used to measure cultural dimensions.

Individuals were first presented with a hypothetical proposition to fund the collective choice mechanism. If the referendum passed, each individual in the group hypothetically bought a bottle of water. The instructions were as follows:

For the first experiment, you will vote on a hypothetical proposition. Suppose there was a proposition that 
everyone in this room would pay $\$ 0.30$ and everyone would receive a 24 ounce bottle of water. If more than half the people in this room vote for the proposition, then everyone would pay $\$ 0.30$ and everyone would receive a 24-ounce bottle of water. If more than half the people in the room vote against the proposition, no one would pay anything and no one would buy or receive water. If it is a split vote, I will flip a coin to determine the outcome. If it is heads, everyone will have to buy water. If it is tails, no one would buy or receive water. Although this vote is hypothetical, please vote as though the outcome of the vote were real. ${ }^{7}$

The subjects voted on the referendum and moved onto another set of unrelated experiments. ${ }^{8}$ The results from the hypothetical vote and all other experiments were not revealed until after the second referendum. In the second referendum, subjects were presented with the same proposition to fund the public good, except that the vote was real in this case. Instructions for the second vote began with "At the beginning of this session, you voted, hypothetically, on a proposition to buy bottled water. Now, we are going to vote, for real, on the proposition." The directions continued as in the first vote, but without any hypothetical wording. Actual bottles of water were brought into the view of subjects to reinforce the real aspect of the new vote. The directions informed the subjects that if the group chose to buy water, then the cost of the water would be deducted from each person's total earnings at the end of the experimental session (see the Appendix).

\footnotetext{
${ }^{7}$ Note, there were no bottles of water visibly present in the hypothetical referendum. This part of the experimental design reinforces the hypothetical nature of the referendum. It is, however, plausible that the absence of a visual cue may leave less experience subjects uncertain of the actual bottle size. While this is plausible, we felt it was more important to retain the truly hypothetical nature of the initial referendum. The hypothetical nature of the referendum mirrors many hypothetical situations, especially in environmental policy valuation work, in which the consumer may be asked to value of state of nature that has yet to exist.

${ }^{8}$ Subjects anonymously participated in time preference, risk preference, ultimatum bargaining, and voluntary contribution mechanism experiments in addition to the hypothetical bias experiment. The identities were anonymous through all experiments and results (earnings) were not revealed until the second or real vote in the hypothetical bias experiment.
}

Several aspects of our experimental design are worth mentioning. First, the prices and surveys were converted and translated into local currency and language in each country. The price of water in each country was based on a purchasing power parity index conversion for the price of water in the United States. The purchasing power parity index developed by the World Bank (2004) ensures the earnings a subject received in one of the countries would have the same relative buying power of the payment received by other subjects in other countries. It should be noted that the rate of hypothetical bias is not dependent on this conversion factor; however, using such a conversion factor does make both the hypothetical and real transactions more comparable across locations. In addition, conversions were made to adjust for differences in the size of water bottles in each country.

Second, as discussed in Carson, Groves, and Machina (2007), the closed referendum format of the collective-choice mechanism makes the good non-excludable, non-rival, and the mechanism incentive-compatible. A true public good contribution, such as a contribution to the Red Cross, was not used because the "openness" of this experimental referendum environment renders the mechanism non-incentive compatible; that is, people do not have to donate in the experiment and can free-ride on contributions of others. Third, our approach uses a within-subject design. The advantage of such an approach is that it holds constant individual-specific factors and isolates the treatment effect in a more powerful way than could be carried out in a between-subject test. Fourth, we pre-announcing that, on average, the subjects would earn a given dollar value in the experiment to prevent the possibility that differences in subject's expectations in earned income would cause differences in behavior. This pre-announced expected earning was equivalent (i.e., converted using the World Bank's purchasing power parity index) across locations. Finally, the number of subjects in each experimental session varied from 10 to 16 , and we gathered a total of 346 observations (63 
from Indiana, 57 from Kansas, 96 from China, 60 from Niger, and 70 from France).

\section{RESULTS}

A summary of our referendum data across the various treatment/location cells is presented in Table 1. A striking result is that Nigerian subjects were more likely to vote "yes" in the real rather than the hypothetical referendum. Consistent with the extant literature, U.S. subjects predominately vote in favor of the proposition in the hypothetical treatment, but then vote against the proposition when the vote has real financial consequences. For example, for Indianans the percent of "yes" votes decreases by $49 \%$ from the hypothetical to the actual treatment, while there is a $23 \%$ decline in the percent of "yes" votes among Kansans. . In stark contrast to the United States, empirical results for the Nigerians highlight the dangers of benefit transfer in this case: there is a $25 \%$ increase in the percentage of Nigerians who vote "yes" across the hypothetical and real votes.

As the results in the last four columns in Table 1 highlight, this result is driven by the $33 \%$ of Nigerians who voted "no" in the hypothetical regime and "yes" in the real regime. As aforementioned, given that (1) subjects were carefully made aware of their expected earnings before the hypothetical experiment began, and (2) the expected earnings have the same purchasing power parity equivalence across locations, we doubt that this result is driven by higher income effects among Nigerians. The empirical results for the other two locationsChina and France - indicate subject behavior in those locations falls between the U.S. and Nigerien locations.

To determine whether the proportion of people that fell into each of the four

\footnotetext{
${ }^{9}$ The Turnbull estimate of the lower bound of willingness-to-pay for water, obtained by multiplying the percentage of subjects voting "yes" to the vote and the price of the water, in Indiana (Kansas) changes from $\$ 0.23$ in the hypothetical referendum to $\$ 0.08$ in the real referendum ( $\$ 0.18$ to $\$ 0.12$ ) per 24 oz.-bottle of water (Haab 2000).
}

response categories (yes-yes, no-no, yesno, and no-yes) was independent of location, several statistical tests were used including Chi-Square tests as well as a multinomial logit model. We can strongly reject the hypothesis that five locations are independent of the four response categories (yes-yes, no-no, yes-no, and no-yes) according to a Chi-Square tests $\left(\chi^{2}=99.03 ; p<\right.$ $0.01)$. This implies that type and degree of hypothetical bias differs significantly across the five locations. Because we can reject the overall hypothesis that the five locations are independent of the four response categories, we now turn to pair-wise tests to determine whether there are significant differences in the type and degree of hypothetical bias across each location pair. Homogeneity is rejected at the $p<0.05$ level according to a Chi-Square test for all 2-tuples, expect for Kansas/Indiana, Kansas/France, and France/Niger, where it is rejected at the $p$ $<0.10$ level. Such results underscore that even in cases where homogeneity can plausibly be assumed (i.e., Kansas and Indiana), hypothetical bias varies enough to render benefit transfer unreliable. ${ }^{10}$

To further investigate this issue, a multinomial logit model was estimated to test whether the above results persist after controlling for gender. The dependent variable in the multinomial logit model represents the all four potential categories of responses (yes-yes, no-no, yes-no, and noyes). Even after controlling for gender, there are significant differences in the likelihood of respondents from each location falling into each response category. The Chinese and Indianan subjects were $13 \%$ and $30 \%$ more likely to vote yes-no than the French subjects. Subjects in Kansas and China were less likely to vote no-no than the French subjects. Nigeriens were the only subjects more likely to vote no-yes than the French subjects. Overall, women exhibit a higher propensity to vote yes-no than men.

\footnotetext{
${ }^{10}$ The within location differences in directional hypothetical bias are not significant. Chi-square statistical tests reveal less variance in the frequency of hypothetical bias within locations than across locations.
} 


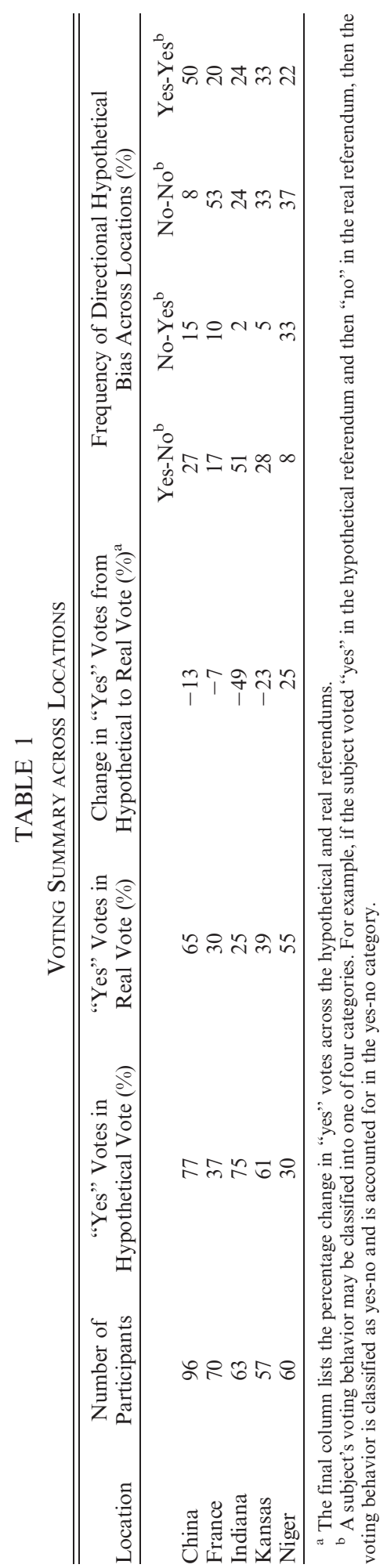


After finding significant differences in hypothetical across locations, we test whether culture affects hypothetic bias using a reduced-form binary logit model, where the dependent variable takes the value of one if a person exhibited hypothetical bias (either yes-no or no-yes) and the value of zero if a person exhibited no hypothetical bias (yes-yes, or no-no). Our hypotheses relating culture to hypothetical bias are motivated by previous experimental economic work demonstrating that differences in economic behavior exist across individuals in different cultures (Henrich et al. 2001; Roth et al. 1991). Smith (2003) suggests that ecological rationality offers a framework to explain these differences in behavior across groups and cultures. Following this ecological rationale, human reasoning evolves as societies proceed through different biological and cultural evolutionary processes. A person's reasoning is based on experience and knowledge passed on by other humans around $\mathrm{him} / \mathrm{her}$.

Hofstede $(1980,1991)$ developed a framework to identify cultural differences which we employ to explore the influence of culture on hypothetical bias. Hofstede identified five dimensions by which culture may vary: power distance, individualism, masculinity, uncertainty avoidance, and long-term orientation. Measures of these dimensions are used as explanatory variables, along with gender, in the logit model. "Power distance" is a measure of the degree of human equality in a society. It is a part of all boss-subordinate relationships and depends on the subordinate's need for security and dependence as well as the boss's ability to provide leadership. "Individualism" in a society defines the relationship between individuals and their social groups, especially family. People in more collective societies live in extended families and tribes. People in individualistic societies tend to live as singles or in nuclear families. Societies with high regard for "masculinity," place more value on achievement, selfreliance, assertiveness, aggression, exhibition, dominance, and autonomy. Societies with more feminine features value nurturance, responsibility, obedience, sensitivity to social interdependence, affiliation, and humility. "Uncertainty avoidance" affects how people interpret risks in their environment through rule orientation, employment stability, and stress as indicators of uncertainty avoidance within a society. Uncertainty avoidance is controlled by technology, rules (laws), and rituals (Hoftstede 1980). "Long-term orientation" focuses on thriftiness and perseverance. Individuals with short-term orientation are more concerned with respecting tradition, saving "face," and meeting social obligations (Hofstede 1991).

To gather these five measures, we had each subject respond to a series of survey questions modified from Hofstede (see Appendix). Responses to these questions are used to calculate a score for each of the five cultural dimensions. Each score can take a value ranging from less than 0 to 100 , based on computational procedures set forth by Hofstede. For example, if a subject has an individualism score of 70 , then they are highly individualistic; a subject with a score of 30 is collectivistic. For the regression analysis, we converted the scores into a binary variable: all scores in a particular cultural dimension with a value greater than 50 are coded as one, and scores less than 50 are assigned a value of zero.

The results for the binary logit model are presented in Table 2. Again, the dependent variable takes a value of 1 for individuals who gave an inconsistent response to the hypothetical and real valuation questions (i.e., voted yes-no or no-yes) and a 0 for individuals who exhibited no hypothetical bias (i.e., voted yes-yes or no-no). The independent variables in this model include gender-location interactions, the binary cultural scores discussed above, and location dummy variables. We interact gender and location-specific dummy variables to determine whether the propensity for women to exhibit a higher degree of hypothetical bias is constant across location.

Empirical results, which are presented in Table 2, suggest that Kansas is the only 
TABLE 2

Logit Model Marginal Effects Estimates

\begin{tabular}{lcc}
\hline \hline Variable & Coefficient & Standard Error \\
\hline Constant & -0.5501 & 0.1399 \\
Indiana & $0.2985^{* *}$ & 0.1332 \\
Kansas & -0.0539 & 0.1561 \\
China & $0.2616^{* *}$ & 0.1187 \\
Niger & $0.2876^{* *}$ & 0.1234 \\
Female*Indiana & 0.0907 & 0.1325 \\
Female*Kansas & $0.3087^{* *}$ & 0.1492 \\
Female*China & -0.0646 & 0.0948 \\
Female*Niger & -0.0608 & 0.1230 \\
Female*France & 0.1581 & 0.1377 \\
Power Distance & $-0.1023^{*}$ & 0.0573 \\
Masculinity & $0.1716^{* * *}$ & 0.0574 \\
Long-Term Orientation & 0.0414 & 0.0552 \\
Individualism & $0.1381^{* *}$ & 0.0618 \\
Uncertainty Avoidance & 0.0212 & 0.7310 \\
\hline
\end{tabular}

Notes: The dependent variable is the subject's voting behavior across the hypothetical and real votes, and takes on a one, if the subject changes his vote from the hypothetical to real vote and is zero, otherwise. Parameter estimates are marginal effects computed at the sample means.

The model's likelihood ratio is 32.3 , which is statistically significant at the $99.5 \%$ level.

$* * *=$ Significant at the $99 \%$ level; $* *=$ significant at the $95 \%$ level; * = significant at the $90 \%$ level.

location with a gender effect: Kansan women are $31 \%$ more likely to display hypothetical bias than Kansan men. ${ }^{11}$ Thus, the driving force behind the results with respect to gender in the previous multinomial logit model analysis is likely the behavior of Kansans. With respect to cultural variables, we find that more masculine people are $17 \%$ more likely to display hypothetical bias than feminine societies. ${ }^{12}$ Likewise, more individualistic people are $14 \%$ more likely to display hypothetical bias than feminine people. The only other cultural variable that is (marginally) significant is power distance, which indicates that people with high levels of power distance

\footnotetext{
${ }^{11}$ We note that a multinomial logit model was specified for this inner location gender difference test as well. Due to a lack of observations of women who changed their vote from "no" to "yes" in Kansas and Indiana, this model collapsed. Thus, this difference in hypothetical bias between men and women is only caused by women's increased likelihood of changing from "yes" to "no".

12 One may suspect the "masculinity" and female demographic variables are related. For example, female subjects would be more likely to have a lower masculinity score. This, however, is not the case. The female dummy variable and masculinity variable are not correlated overall $(\rho=0.07, p=0.2161)$.
}

are $10 \%$ less likely to exhibit hypothetical bias than people with lower levels of power distance. Meanwhile, the location dummy variables for Indiana, China, and Niger continue to be significant indicating there may be additional, unmeasured cultural or societal factors still present and effecting hypothetical bias in the different locations.

The combined statistical significance of the three individual cultural variables presented in Table 2 allows us to provide a tentative explanation of the observed hypothetical bias across space. In individualistic cultures, there tends to be greater distance between the private self and the social self, and individuals are free to explore their own wants, needs, and desires. In collectivist cultures, however, one's private concept of self is highly dependent on interpersonal relationships and it is not "free," especially in more hierarchical cultures (Ting-Toomey 1985). Likewise, masculine societies place more weight on autonomy and individual decision making and have less regard for the collectivist good, thereby inducing greater hypothetical bias. Our assertion in this case is that such measures most likely have a reduced-form relationship to hypothetical bias and this understanding can help us 
make better informed benefit transfer estimates.

\section{CONCLUSIONS}

Economic models ubiquitously make panhuman assumptions about behavior of economic agents. Recent laboratory research has suggested that cultural effects might be important in certain bargaining settings (e.g., Henrich 2000; Henrich et al. 2001; Roth et al. 1991) and in the degree of cooperative behavior in social dilemmas (e.g., Portney and Probst 1999). Yet, despite its policy relevance, scholars and policymakers have assumed agents' responses to contingent questions, which are popular tools in benefit-cost analysis, are isomorphic across cultures. This study challenges this assertion by exploring behavior across different cultures - from the United States to Europe to Africa to Asia. We find a significant difference in behavior across groups. We also find that measures of subjects' cultural values may serve a role in explaining these differences. These results have both positive and normative implications. From a policy perspective, because benefit-cost analyses are now required at the federal level, and are increasingly being used by foreign governments and international bodies, these findings speak directly to the reliability of the benefit-transfer technique.

Future work should focus on other factors that might influence empirical estimates of hypothetical bias. For example, Henrich et al. (2001) found societies' market integration was related to reciprocal behavior. In our study, we have only five location observations for market integration. Via casual observation, however, we note that the individuals in the less developed economies (China and Niger) were more prone to "positive" hypothetical bias-where subjects voted "no" in the hypothetical vote and "yes" in the real vote-than subjects in the developed countries. Understanding this phenomenon and further investigation of cultural influences on hypothetical bias will improve our understanding of inter-location differences in hypothetical bias and, thus, improve the reliability of benefit transfer and other CVM related measures.

\section{APPENDIX}

\section{EXPERIMENT 1 INSTRUCTIONS}

$<<$ Read the following instructions with regard to bottled water. Note, while you are doing this part of this experiment, the bottled water for the second part of the experiment should not be visible to participants. It would be nice if it is somewhere cool. $>>$

For the first experiment, you will vote on a hypothetical proposition. Suppose there was a proposition that everyone in this room would pay $\$ 0.30$ and everyone would receive a 24 ounce bottle of water. If more than half the people in this room vote for the proposition, then everyone would pay $\$ 0.30$ and everyone would receive a 24 ounce bottle of water. If more than half the people in the room vote against the proposition, no one would pay anything and no one would buy or receive water. If it is a split vote, I will flip a coin to determine the outcome. If it is heads, everyone will have to buy water. If it is tails, no one would buy or receive water. Although this vote is hypothetical, please vote as though the outcome of the vote were real. You will use the Experiment 1 Ballot to vote. Are there any questions?

$<<$ Answer any questions. $>>$

Please vote now. When you are through put down your pen and stay in your seat. I will pick up your ballot.

\section{Experiment 1 Ballot}

Bottled Water Voting Card for Participant Number

Please circle your response to the following question.

Question: Do you support the opportunity to buy bottled water for $\$ 0.30$ per 24 oz. bottle? (Please check one of the following)

A. Yes, I support buying bottled water for $\$ 0.30$ per 24 oz. bottle.

B. No, I do not support buying bottled water for $\$ 0.30$ per $24 \mathrm{oz}$. bottle.

At the beginning of this session, you voted, hypothetically, on a proposition to buy bottled water. Now, we are going to vote, for real, on 
the proposition. $<<$ Show them the water you have. It should be hidden until this point. $>>$ The proposition is that everyone in this room would pay $\$ 0.30$ and everyone would receive a 24 ounce bottle of water. If more than half the people in this room vote for the proposition, then everyone would pay $\$ 0.30$ and everyone would receive a 24 ounce bottle of water after the vote. The $\$ 0.30$ will be deducted from your total earnings at the end of the experiment. If more than half the people in the room vote against the proposition, no one will pay anything and no one will receive or buy water. If it is a split vote, we will flip a coin to determine the outcome. $\mathrm{f}$ it is heads, everyone will have to buy water. If it is tails, no one will buy or receive water.

Please fill out the following Experiment 5 Ballot and give it to me. Once all ballots are received, I

\section{Experiment 5 Ballot}

Bottled Water Voting Card for Participant Number

Please check your response to the following question.

Question: Do you support the opportunity to buy bottled water for $\$ 0.30$ per $24 \mathrm{oz}$. bottle? (Please check one of the following)

A. Yes, I support buying bottled water for $\$ 0.30$ per 24 oz. bottle.

B. No, I do not support buying bottled water for $\$ 0.30$ per $24 \mathrm{oz}$. bottle.

will count the votes to determine if the group will be buying water or not.

$<<$ If the group votes to buy water, they must all buy water. Please be sure to record the payment for the bottle of water on the subject's earning form. $>>$ 


\section{VSM SURVEY QueSTIONS*}

A. Directions: Please think of an ideal university, disregarding your present university. In choosing an ideal university, how important would it be to you to... (Please circle one answer on each line across):

Utmost High Moderate Little Very Little

Importance Importance Importance Importance Importance

1. have sufficient time for your personal life.

2. have good physical working conditions (good ventilation and lighting, adequate work space, etc.).

3. have a good working relationship with your professor(s).

4. have security of employment.

5. work with people who cooperate well with one another.

6. be consulted by your professor in his/her decisions.

7. have an opportunity for advancement to higher degrees (e.g. medical, law, and graduate degrees).

8. have an element of variety and adventure in your education.

$\begin{array}{lllll}1 & 2 & 3 & 4 & 5 \\ 1 & 2 & 3 & 4 & 5 \\ 1 & 2 & 3 & 4 & 5 \\ 1 & 2 & 3 & 4 & 5 \\ 1 & 2 & 3 & 4 & 5 \\ 1 & 2 & 3 & 4 & 5 \\ 1 & 2 & 3 & 4 & 5 \\ 1 & & & & \\ & & 3 & 4 & 5\end{array}$

B. Directions: In your private life, how important is each of the following to you? (Please circle one answer on each line across):

\begin{tabular}{lccccc}
\hline \hline & $\begin{array}{c}\text { Utmost } \\
\text { Importance }\end{array}$ & $\begin{array}{c}\text { High } \\
\text { Importance }\end{array}$ & $\begin{array}{c}\text { Moderate } \\
\text { Importance }\end{array}$ & $\begin{array}{c}\text { Little } \\
\text { Importance }\end{array}$ & $\begin{array}{c}\text { Very Little } \\
\text { Importance }\end{array}$ \\
\hline 9. Personal steadiness and stability & 1 & 2 & 3 & 4 & 5 \\
10. Thrift & 1 & 2 & 3 & 4 & 5 \\
11. Persistence (perseverance) & 1 & 2 & 3 & 4 & 5 \\
12. Respect for tradition & 1 & 2 & 3 & 4 & 5 \\
\hline
\end{tabular}

C. Directions: Please read the following statements and then circle the answer you agree with.

13. How often do you feel nervous or tense at school?

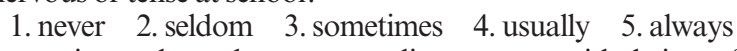

14. How frequently, in your experience, do students express disagreement with their professors?

$\begin{array}{lllll}1 \text {. very seldom } & 2 \text {. seldom } & 3 \text {. sometimes } & 4 \text {. frequently } & 5 \text {. very frequently }\end{array}$

D. Directions: Please rate each statement by the extent that you agree or disagree with each of the following statements? (Please circle one answer in each line across):

\begin{tabular}{|c|c|c|c|c|c|c|}
\hline & & $\begin{array}{c}\text { Strongly } \\
\text { Agree }\end{array}$ & Agree & Undecided & Disagree & $\begin{array}{l}\text { Strongly } \\
\text { Disagree }\end{array}$ \\
\hline 15. & Most people can be trusted & 1 & 2 & 3 & 4 & 5 \\
\hline 16. & $\begin{array}{l}\text { One can be a good teacher without having precise } \\
\text { answers to most questions that students may } \\
\text { raise about their work }\end{array}$ & 1 & 2 & 3 & 4 & 5 \\
\hline 17. & $\begin{array}{l}\text { An organization structure in which certain } \\
\text { subordinates have two bosses should be } \\
\text { avoided at all costs }\end{array}$ & 1 & 2 & 3 & 4 & 5 \\
\hline 18. & $\begin{array}{l}\text { Competition between students usually } \\
\text { does more harm than good }\end{array}$ & 1 & 2 & 3 & 4 & 5 \\
\hline 19. & $\begin{array}{l}\text { A company's or an university's rules should not } \\
\text { be broken - not even when the student thinks } \\
\text { it is in the school's best interest }\end{array}$ & 1 & 2 & 3 & 4 & 5 \\
\hline & $\begin{array}{l}\text { When people have failed in life it is } \\
\text { often their own fault }\end{array}$ & 1 & 2 & 3 & 4 & 5 \\
\hline
\end{tabular}

\footnotetext{
$\$$ The survey questions are adapted to represent teacher-pupil rather than boss-worker relationships.
} 


\section{References}

Bateman, Ian J., Roy Brouwer, Stavros Georgiou, Nick Hanley, Fernando Machado, Susana Mourato, and Caroline Saunders. 2005. "A 'Natural Experiment' Approach to Contingent Valuation of Private and Public UV Health Risk Reduction Strategies in Low and High Risk Countries." Environmental and Resource Economics 31 (1): 47-72.

Brouwer, Roy, and Ian J. Bateman. 2005. "Benefits Transfer of Willingness To Pay Estimates and Functions for Health-Risk Reductions: A Cross-Country Study." Journal of Health Economics 24 (3): 591-611.

Carson, Richard, Theodore Groves, and Mark Machina. 2007. "Incentive and Informational Properties of Preference Questions." Environmental and Resource Economics 37 (1): 181-210.

Champ, P., and R. C. Bishop. 2001. "Donation Payment Mechanisms and Contingent Valuation: An Empirical Study of Hypothetical Bias." Environmental and Resource Economics 19 (4): 383-402.

Douglas, Mary. 1985. Social Research Perspectives. Beverly Hills: Russell Sage Publications.

Haab, Timothy C., and Kenneth E. McConnell. 2000. Valuing Environmental and Natural Resources. Northampton, Mass.: Edward Elgar Pub., Inc.

Henrich, Joseph. 2000. "Does Culture Matter? Ultimatum Bargaining Among the Machiguenga of the Peruvian Amazon." The American Economic Review 90 (4): 973-79.

Henrich, Joseph, Robert Boyd, Samuel Bowles, Camerer Colin, Ernst Fehr, Herbert Gintis, and Richard McElreath. 2001. "In Search of Homo Economicus: Behavioral Experiments in 15 Small-Scale Societies." The American Economic Review 91 (2): 73-78.

Hofstede, Geert. 1980. Cultures Consequences. Beverly Hills: Sage Publications.

1991. Cultures and Organizations: Software of the Mind. Berkshire, U.K.: McGraw-Hill.

Johannesson, M., G. C. Blomquist, K. Blumensche, P. O. Johannsson, B. Liljas, and R. M. O'Conor. 1999. "Calibrating Hypothetical Willingness to Pay Responses." Journal of Risk and Uncertainty 18 (1): 21-32.

List, John A. 2004. "Neoclassical Theory versus Prospect Theory: Evidence from the Marketplace." Econometrica 72 (2): 615-25.
List, John A., and Craig A. Gallet. 2001. "What Experimental Protocol Influence Disparities Between Actual and Hypothetical Stated Values?" Environmental and Resource Economics 20 (3): 241-54.

List, John A., Robert Berrens, Alok Bohara, and Joe Kerkvliet. 2004. "Examining the Role of Social Isolation on Stated Preferences." American Economic Review 94 (3): 741-52.

Lusk, J. L., and F. B. Norwood. 2008. "An Inferred Valuation Method." Working paper. Department of Agricultural Economics, Oklahoma State University.

Norwood, B., J. L. Lusk, and T. Boyer. 2008. "Forecasting Hypothetical Bias: A Tale of Two Calibrations." In Experimental Methods, Environmental Economics, ed. T. L. Cherry, S. Kroll and J. F. Shogren,

Portney, Paul R., and Katherine Probst. 1999. The RFF Reader in Environmental and Resource Management. Washington, D.C.: Resources for the Future.

Ready, Richard, and Ståle Navrud. 2006. International Benefit Transfer: Methods and Validity Tests. Ecological Economics 60 (2): 42934.

Ready, Richard, Ståle Navrud, Brett Day, Richard Dubourg, Fernando Machado, Susana Mourato, Frank Spanniks, and Maria Xosé Vázquez Rodriquez. 2004. "Benefit Transfer in Europe: How Reliable Are Transfers between Countries?" Environmental and Resource Economics 29 (1): 67-82.

Roth, Alvin E., Vesna Prasnikar, Masahiro Okuno-Fujiwara, and Shmuel Zamir. 1991. "Bargaining and Market Behavior in Jerusalem, Ljubljana, Pittsburgh, and Tokyo: An Experimental Study." The American Economic Review 81 (3): 1068-95.

Smith, Vernon L. 2003. "Constructivist and Ecological Rationality in Economics." The American Economic Review 93 (3): 465508.

Ting-Toomey, Stella. 1985. "Toward a Theory of Conflict and Cultures." In Communication, Culture, and Organizational Processes, ed. William B. Gudykunst, Lea P. Stewart and Stella Ting-Toomey. Beverly Hills: Sage Publications.

World Bank. 2004. World Development Indicators. Washington, D.C.: World Bank. 